\title{
SEMIÓTICA DAS CULTURAS NATURAIS EM SUSPIROS POÉTICOS E SAUDADES, DE GONÇALVES DE MAGALHÃES
}

\author{
SEMIOTICS OF NATURAL CULTURES OF GONÇALVES DE MAGALHÃES' \\ SUSPIROS POÉTICOS E SAUDADES (POETIC SIGHS AND NOSTALGIAS)
}

Fábio Kawati

Programa de Pós-Graduação em Ensino de
Ciências da Natureza e Matemática
UFMT / Câmpus de Sinop
juninhofk@yahoo.com.br
Felício Guilardi Júnior
UFMT / Câmpus de Sinop
fifo2801@gmail.com
Marieta Prata de Lima Dias
UFMT / Câmpus de Sinop
marietaprataldias@gmail.com

Resumo: A relação entre Literatura e Ciências da Natureza nem sempre é muito explorada. Esta pesquisa dedicou-se a perscrutar essa relação, em busca de observar o conhecimento científico desvelado na poeticidade constante no período do Romantismo. Neste artigo, o enfoque ocorre em poemas presentes em "Suspiros Poéticos e Saudades", maior obra de Gonçalves de Magalhães, considerado o precursor do Romantismo no Brasil. Esses poemas apresentam elementos associados aos conhecimentos científicos da área de Ciências Naturais. Identificar, investigar e comparar a presença de tais informações na Literatura permitem, muitas vezes, uma visão diferenciada acerca da compreensão de situações cotidianas e/ou de fatos históricos, além de apresentar a perspectiva de experienciar o gênero poema sob o olhar da Semiótica das Culturas.

Palavras-chave: Ciências da Natureza. Literatura. Gonçalves de Magalhães. Semiótica da Cultura.

Abstract: The relationship between literature and natural sciences is not always too much explored. This research spent scrutinizing this relationship, seeking out watch the displayed scientific knowledge in the constant poeticity in the Romantic Era. In this article, the priorities result is located on poems in Suspiros e Saudades (Poetic Sighs and Nostalgias), Gonçalves de Magalhães' greatest work, considered the precursor of Romanticism in Brazil. These poems present associated elements to the scientific expertise in the field of Nature Science. Identifying, investigating, and comparing the presence of such information in literature often brings a different view of understanding everyday 
situations and / or historical facts, and is another perspective of experiencing the poem genre, under the view of Semiotics of Culture.

Keywords: Natural Sciences. Literature. Gonçalves de Magalhães. Semiotics of Culture.

\section{Introdução}

O Romantismo no Brasil surgiu como resposta aos anseios nacionalistas, principalmente após a Independência, em 1822. O precursor desse movimento literário ou escola literária no Brasil foi Gonçalves de Magalhães, compositor da obra Suspiros Poéticos e Saudades. Em alguns poemas dessa obra, aparecem elementos relacionados ao campo de estudo das Ciências da Natureza, apresentados, na maioria dos casos, para exaltar o nome de Deus ou explicar fatos históricos. Esses elementos são signos. Signos são objeto da Semiótica. Consideramos, com Rastier (2013, p. 142) que o "estudo das línguas é uma das subdivisões da semiótica". Na abordagem deste estudo, são construídas interpretações de fatos humanos e sociais observados em poemas escritos em dois séculos anteriores. Fatos expostos artisticamente em poemas e aqui vistos à luz dos conhecimentos atuais das Ciências da Natureza.

As ciências da natureza e da vida e, sob outro aspecto, as ciências lógico-formais, estabelecem os fatos, eliminando do seu campo de atuação julgamentos de valor que, para elas, são apenas pássaros pré-conceituosos: por exemplo, se em todas as culturas, existem animais puros e impuros, para a zoologia, esta distinção é, num primeiro momento, caduca; se o corpo humano faz, em toda parte, objeto de interdições mágicas ou religiosas, a anatomia foi constituída, emancipandose deles, etc. (RASTIER. 2015a, p. 20)

Assim pensando, estamos no campo da Semiótica das Culturas.

Como as línguas são obras humanas mais que produtos providenciais da evolução, as oposições sumárias entre inato e adquirido, natureza e cultura devem ser relativizadas. Esta tarefa cabe à semiótica das culturas, para evitar que nossa espécie desapareça antes mesmo de ser descrita. (RASTIER, 2019, p. 188

O leitor dos poemas é levado a buscar certos conhecimentos para compreender a mensagem dos poemas. O poema é enigmático. Por isso, não basta lê-lo superficialmente. Às vezes, é necessário esmiuçar cada estrofe, verso ou palavra ou até mesmo a biografia do poeta e o contexto da época, para que seja possibilitada a compreensão daquilo que está nele expresso. A transmissão do sentido produzido nessa compreensão passa, pois, por recontextualização, transformação e reelaboração (RASTIER, 2015b, 494). 


\section{O século das luzes e a escola romântica}

Após a Revolução Científica, do século XVII, no Iluminismo, conhecido como Século das Luzes, o homem se descobre como ser pensante e gerencia grandes revoluções, tanto na Filosofia quanto na ciência em geral (CHASSOT, 2004).

"A humanidade, que antes aprendera mais acerca do universo, descobre agora que não precisa de tutores para pensar. A Enciclopédia e a Revolução Francesa são dois legados desse período, aos quais se junta a Revolução Lavoisieriana" (CHASSOT, 2004, p. 165). O primeiro volume da Enciclopédia foi publicado no Brasil duzentos e trinta e oito anos após seu lançamento.

A partir das últimas décadas do século XVIII, o Romantismo desenvolveu-se por toda a Europa num cenário marcado pela ascensão da burguesia, classe diretamente ligada ao Liberalismo, frente aos aristocratas. Com isso, o campo literário também sofreu grandes mudanças. Em Portugal, a escola romântica fixou-se após as lutas entre D. Miguel e D. Pedro I; aquele pregava o Absolutismo enquanto este defendia o Liberalismo. Grande parte dos escritores portugueses da época apoiaram D. Pedro I, fato que desencadeou o processo de exílio de muitos deles. Por isso, é bastante forte o traço nacionalista em textos portugueses dessa época (CADEMARTORI, 1987). No Brasil, o Romantismo seguiu algumas tendências, como Indianismo, Nacionalismo, Mal do Século, Liberalismo, Abolicionismo e Saudosismo. A visão bucólica do Arcadismo, escola literária anterior ao Romantismo, deu lugar ao subjetivismo, nacionalismo e às emoções à flor da pele, tendendo para um sentimentalismo quase santo, intocável, inacessível em alguns casos. A escola literária romântica no Brasil passou por três gerações, a saber:

$1^{\text {a }}$ GERAÇÃO: Dentre as temáticas dessa geração estão: religião, misticismo, natureza, indianismo e nacionalismo. Os autores que mais se destacaram são: Gonçalves de Magalhães, Gonçalves Dias e José de Alencar;

2a GERAÇÃO: Individualismo, subjetivismo e o "mal do século" são os pontos mais marcantes. Casimiro de Abreu, Álvares de Azevedo e Fagundes Varela estão entre os escritores dessa geração;

$3^{\text {a }}$ GERAÇÃO: Conhecida também por Condoreirismo, é destacada pelas temáticas sociais, entre elas, o Abolicionismo. Seu principal nome é Castro Alves. (SILVA; BERTOLIN, 1999)

\section{O romantismo de Gonçalves de Magalhães}

Domingos José Gonçalves de Magalhães ou somente Gonçalves de Magalhães, nome pelo qual é mais conhecido, foi médico, diplomata, poeta e dramaturgo, nascido no Rio 
de Janeiro em 13 de agosto de 1811 e falecido em Roma, na data de 10 de junho de 1882. Considerado o precursor do Romantismo no Brasil, sua principal obra - Suspiros Poéticos e Saudades (escrita em Paris, em 1836) - contém vários poemas (MAGALHÃES, s.d.). São características peculiares dessa obra a devoção ao Cristianismo e o espírito nacionalista. O poeta ainda foi um dos responsáveis pela redação de Nitheroy, revista brasiliense, que continha matérias sobre Literatura e Ciência.

Em 1822, foi proclamada a Independência do Brasil por D. Pedro I, e fez-se necessário construir, paulatinamente, a imagem de um novo país, agora liberto do colonialismo português. Isso refletiu em diversas áreas, inclusive na Literatura. No Brasil, passados os períodos da Literatura de Informação, Barroco e Arcadismo, com características fortemente lusitanas, iniciou-se um novo período, evidenciado inicialmente pelo intenso sentimento nacionalista, baseado no rosto e na alma do povo brasileiro.

Suspiros Poéticos e Saudades expressa enorme devoção a Deus e ao Cristianismo, muitas vezes, com ar de melancolia. Outra característica notável da obra é o nacionalismo, peculiar aos autores da $1^{\mathrm{a}}$ geração romântica.

\section{Elementos das ciências da natureza na obra Suspiros Poéticos e Saudades}

A relação entre linguagem e cultura se dá em três sentidos diferentes. Primeiro, a linguagem é uma forma primária de cultura do espírito criador do homem; segundo, a linguagem reflete a cultura não linguística, é atualidade da cultura, manifesta os saberes, as ideias, as crenças acerca da realidade conhecida, das realidades sociais e da própria linguagem enquanto parte dessa realidade; terceiro, a linguagem não é só competência linguística, mas é competência extralinguística, conhecimento de mundo, saberes, ideias e crenças acerca das coisas. (COSERIU ${ }^{1}$ apud ARAGÃO, 2020).

Os três sentidos da mencionada relação entre linguagem e cultura são, pois, constantes em Suspiros Poéticos e Saudades, de Gonçalves de Magalhães. Por exemplo, no poema "Deus, e o homem", o fenômeno vulcanismo é apresentado.

Uma voz, como o eco das cavernas,

Quando os ventos nos ares se debatem;

Como um ronco do Oceano repelido

Por estável penedo; como um grito

Das entranhas da terra, quando acesas

De sua profundez lavas borbotam...

(MAGALHÃES, s.d., p. 16. Grifo nosso)

\footnotetext{
1 COSERIU, E. Fundamentos e tarefas da sócio e etnolinguística. In: MELLO, Lynalda de A. (org.). Sociedade, cultura e língua: ensaios de sócio e etnolinguística. João Pessoa: Shorin, 1990. p. 39-40
} 
O uso de elementos da Astronomia também é comum. Em outro trecho do poema, o poeta menciona o movimento harmônico. Esse tipo de movimento, amplamente estudado pela Física, é relacionado à onipotência divina. Fica muito claro que, para Gonçalves de Magalhães, Deus não é impedimento para se explicar Ciência.

O movimento harmônico dos orbes

É o hino eterno e místico, que narra

Altamente de um Deus a onipotência.

Tudo revela Deus, - e Deus é tudo.

(MAGALHÃES, s.d., p. 17. Grifo nosso)

"Deus, e o homem" expressa uma intimidade muito grande entre Deus e sua criação, como no trecho a seguir, mencionando que a lua não possui luz própria, tornandose dependente da luz solar.

A lua realiza movimento em volta do seu próprio eixo e possui um ciclo dia-noite, semelhantemente ao planeta Terra, e sua superfície é iluminada pelo sol por período determinado a cada giro completo (LOPES, 2011). Outra observação interessante é a de que a temática "lua", assim como outros elementos da Astronomia, tais como sol, planetas, estrelas, cometas e meteoros, estimulam o ser humano a desenvolver um senso imaginário dos fenômenos astrofísicos e astroquímicos bastante intenso no sentido da imaginação poética e da imaginação científica, aproximando também conhecimento popular e conhecimento científico.

O saber popular não pode ser desprezado, pois é a partir dele que se desenvolvem muitas pesquisas científicas (TAQUARY, 2007). Um exemplo bastante claro disso diz respeito ao uso de plantas medicinais. Grande parte das propriedades terapêuticas dessas plantas, muito antes de serem testadas cientificamente, já era utilizada pela população.

Hoje, a Ciência reconhece que as fases lunares podem influenciar alguns fenômenos naturais devido ao campo gravitacional existente entre a lua e o planeta Terra. No entanto, os povos antigos já acreditavam que as fases da lua possuíam grande influência sobre a vida terrena.

É a tua sublime inteligência,

É a Deus, só a Deus, que tu refletes,

Como do sol a luz reflete a lua.

(MAGALHÃES, s.d., p. 19. Grifo nosso)

Em outro poema, denominado "Os suspiros da pátria", aparece a ideia heliocêntrica do astrônomo e matemático polonês Nicolau Copérnico (1473-1543). A ideia heliocêntrica revolucionou os estudos da Astronomia, pois designou um novo caminho a ser percorrido, dessa vez, em torno do sol e não da Terra. A antiga ideia aristotélico-ptolomaica de geocentrismo sustentou-se por um longo período de tempo; todavia, não era capaz de 
explicar muitos fenômenos, que passaram a ter uma resposta somente a partir da ideia heliocêntrica. Já a menção de círculo perpétuo, apresentado em "Os suspiros da pátria", não condiz com os estudos do astrônomo, astrólogo e matemático alemão Johannes Kepler (1571-1630); segundo esse cientista, os planetas, por exemplo, seguem órbitas elípticas e não circulares, em torno do sol (LEIS DE KEPLER, 2014).

\footnotetext{
Como em torno do sol os astros giram

Em círculo perpétuo,

Em torno do seu Deus as Nações marcham,

E de tal Astro à luz jamais se eclipsam;

Crê em Deus; que ele só salvar-te pode.

(MAGALHÃES, s.d., p. 111. Grifo nosso)
}

O eclipse é conhecido desde a Antiguidade, caracterizado por uma sobreposição de objetos celestes em trânsito (LIMA; ROCHA, 2004). Assim, Deus, supremo criador, não permitiria que sua própria luz fosse "eclipsada" (ocultada) em relação ao ser humano.

Os estudos sobre os eclipses, tanto solares quanto lunares eram vistos de formas diferentes pelos povos antigos. Para os romanos, o eclipse era sinal de que tanto o sol quanto a lua estavam doentes. Sol e lua eram "deuses" que, periodicamente, se enfraqueciam. O primeiro representava a força masculina; já a lua era representante das forças femininas. Para os chineses, o eclipse solar era prenúncio de que o dragão poderia devorar o sol (JANIBELLI; GUIMARÃES, 2006).

Em “Napoleão em Waterloo”, são mencionados, além do eclipse, outros elementos relacionados à Astronomia; todavia, em alguns casos, apenas de forma figurativa, como segue:

Eis aqui o lugar, onde eclipsou-se

$\mathrm{O}$ Meteoro fatal às régias frontes!

E nessa hora em que a gloria se obumbrava,

Além o sol em trevas se envolvia!

Rubro estava o horizonte, e a terra rubra!

Dous astros ao ocaso caminhavam;

Tocado ao seu zênite haviam ambos;

Ambos iguais no brilho, ambos na queda

Tão grandes como em horas de triunfo!

(MAGALHÃES, s.d., p. 117. Grifo nosso)

A Batalha de Waterloo, ocorrida em território belga, entre o exército francês e os aliados Prússia e Inglaterra, foi determinante para a queda de Napoleão, líder do exército francês (BATALHA DE WATERLOO, 2014). No sexto verso, "Dous" significa dois, segundo a tradução do latim para o português (MICHAELIS, 2019). "Ocaso" é o nome dado ao sol quando está se pondo (poente). Já "zênite" (construção imaginária), presente no verso seguinte, é o ponto interceptado por um eixo vertical traçado a partir da cabeça 
de um observador (sobre a superfície terrestre), e que se prolonga até a esfera celeste (ZÊNITE, 2014). Partindo-se dessa constatação, o zênite solar é o instante no qual o sol incide verticalmente sobre um lugar. Pode, ainda, ser denominado o momento da sombra zero, próximo ao meio-dia solar.

“Ocaso", para a imaginação poética, pode representar fraqueza ou fim de ciclo, pois, quando o sol está se pondo, ele não possui a mesma intensidade luminosa na Terra, como no zênite. Assim, o poeta explica a queda do exército francês, utilizando-se da singeleza do poema e ornamentando o fato ocorrido com elementos da Astronomia.

A riquíssima obra de Gonçalves de Magalhães apresenta, também, a tragédia na cidade de Pompeia, Itália, em 79 d.C. (ERUPÇÃO DO VESÚVIO DE 79, 2014), envolvendo a erupção do vulcão Vesúvio. Tal cenário é retratado ainda em “Napoleão em Waterloo”. O poema compara o poder dos inimigos do exército francês na Batalha de Waterloo à potente erupção do vulcão Vesúvio, que trouxe enorme destruição à Pompeia.

\author{
Waterloo! Waterloo!... Lição sublime \\ Este nome revela à Humanidade! \\ Um Oceano de pó, de fogo, e fumo \\ Aqui varreu o exército invencível, \\ Como a explosão outrora do Vesúvio \\ Até seus tetos inundou Pompéia. \\ (MAGALHÃES, s.d., p. 117. Grifo nosso)
}

Verdadeiramente, há muitas controvérsias a respeito de como ocorreu a catástrofe de 79 d. C. A erupção emitiu, além da lava vulcânica, cinzas e gases em altíssimas temperaturas e, Herculano, cidade mais próxima de Pompeia, foi soterrada por lama, água e material vulcânico. A cidade de Pompeia também sofreu grande destruição. Inclusive, fluidos corporais sofreram evaporação instantânea (MUSEU NACIONAL DA UNIVERSIDADE FEDERAL DO RIO DE JANEIRO, s. d).

No poema "A mocidade", cuja composição data de 1835, a Estrela Polar, pertencente à Constelação de Ursa Menor, que coincide com a projeção do eixo terrestre, é mencionada (ESTRELA POLAR, 2014):

Deus em vós ateou do gênio e fogo,

Que a Humanidade guia,

Como a estrela polar o navegante

(MAGALHÃES, s.d., p. 30. Grifo nosso)

A Estrela Polar é visível apenas no Hemisfério Norte e dista cerca de quatrocentos anos-luz do planeta Terra e, por muito tempo, guiou os navegantes (REVISTA VEJA, 2012). 
Gonçalves de Magalhães sempre deixou transparecer sua admiração com relação a grandes nomes de estudiosos do continente europeu. No poema “Ao deixar Paris", os franceses René Descartes (1596-1650) e Nicolas Malebranche (1638-1715) também são lembrados.

O jugo antigo, que a razão curvava, Quebrou, em ti nascido, esse Descartes, Que por novo teor, método novo, Sublime estrada abriu à Inteligência. Malebranche o seguiu, também teu filho (MAGALHÃES, s.d., p. 153. Grifo nosso)

René Descartes (1596-1650), filósofo francês, físico e matemático da Idade Moderna, foi um grande influenciador de outros cientistas e filósofos. Ele sugeriu a fusão entre a Álgebra e a Geometria, originando a Geometria Analítica e o Sistema de Coordenadas. Em sua homenagem, esse Sistema de Coordenadas recebe até hoje o nome de Plano Cartesiano (RENÉ DESCARTES, 2015). No método Cartesiano, baseado na dúvida metódica, duvidase de tudo aquilo que seja claro e distinto (CONEGLIAN et al., 2010).

O francês Malebranche (1638-1715) foi um seguidor das ideias de Descartes. Segundo ele, o mundo não é constituído por matéria, mas por ideias e, enquanto ele for compreendido pelos sentidos do corpo humano, nunca haverá o alcance da verdade, pois o mundo compreendido pelos sentidos é fragmentado (MALEBRANCHE, 2011).

Percebe-se que, mesmo havendo se destacado na Literatura Romântica, Gonçalves de Magalhães também era conhecedor da Filosofia e isso dava um toque diferenciado a seus poemas. Enquanto na criação científica, o sensível é abolido pela tendência a ser racional, na criação poética, a presença de informações científicas e/ou históricas servem de apoio à sensibilidade, inclusive para despertar reações afetivas. Constata-se que, naquela, a imaginação serve somente como passo inicial para a caminhada científica e, nesta, os dados históricos e científicos estão a favor do deleite da imaginação. Como afirma Alencar (2016, p. 132, com base em PAIS, 2000²):

Os sistemas de valores, de crenças e as formas de recriar semioticamente, o mundo são características que definem a identidade de uma cultura em relação as outras. Mas uma cultura não é um sistema fechado. É, ao contrário, produto dos contatos, confrontos ou conflitos com outras culturas, de uma "história compartilhada" com outros agrupamentos humanos.

2 PAIS, Cidmar Teodoro. Considerações sobre a semiótica das culturas: uma ciência da interpretação: inserção cultural, transcodificações culturais. Acta Semiótica et Lingvistica, João Pessoa, v. 14, n. 1, ano 33, 2009. p. 17-30. Disponível em: https://periodicos.ufpb.br/ojs2/index.php/actas/article/view/14616/8267. 


\section{Considerações Finais}

A Literatura Poética é um riquíssimo campo de conhecimentos. Nela, encontra-se a vida de cada poeta, seus anseios e medos e, é claro, sua bagagem de conhecimentos. Percebe-se que Suspiros Poéticos e Saudades, obra mais famosa de Gonçalves de Magalhães, exprime, além de uma elegância muito grande nas palavras, um leque de conhecimentos em áreas diversas. A obra evidencia o contato do escritor com a cultura europeia; fato que não aniquila seu amor pelo Brasil, sua pátria, ou seja, não elimina o nacionalismo presente na $1^{\mathrm{a}}$ geração do Romantismo.

A presença de elementos relacionados às Ciências da Natureza em alguns poemas de Gonçalves de Magalhães auxilia a compreensão de certos fatos por meio da construção imaginária, havendo um paralelo desses fatos com os fenômenos da natureza apresentados. O leitor é levado a elucidar tais fenômenos para a compreensão de acontecimentos históricos, como em "Napoleão em Waterloo". A linguagem do poeta reflete, pois, a cultura do homem do Século das Luzes.

Essa constatação corrobora a noção de que "a língua é vista como uma concepção de mundo, seja como reveladora do modo de vista de uma sociedade e de seus valores culturais, seja como reveladora da estrutura social e das mudanças que ocorrem no seio da sociedade, seja, enfim, como uma estrutura linguística em correlação com as estruturas da sociedade" (FRIBOURG³ apud ARAGÃO, 2020, 24min).

\section{Referências Bibliográficas}

ALENCAR, Adriana Nuvens de. Religiosidade na poesia caririense: uma leitura semiótica de dois sonetos de Geraldo Alencar. Revista Acta Semiotica et Lingvistica, João Pessoa, v. 21, n. 2, p. 131-142, 2016. Disponível em: https://periodicos.ufpb.br/ojs2/index.php/ actas/article/view/32599/17089. Acesso em jun. 2017.

CHASSOT, Ático. Século XVIII: o Século das Luzes. In: CHASSOT, Ático. A ciência através dos tempos. São Paulo: Moderna, 2004. p. 165-186.

ARAGÃO, Maria do Socorro Silva de. Valores literários paraibanos: a pluralidade das formas de expressão. Ciclo de Conferências em Semióticas das Culturas. João Pessoa: UFPB, 2020. Disponível em: https://www.youtube.com/watch?v=vuUfjxS3--k\&feature=youtu. be. Acesso em: 18 ago. 2020.

BATALHA DE WATERLOO. In: WIKIPÉDIA, a enciclopédia livre. Flórida: Wikimedia Foundation, 2014. Disponível em: http://pt.wikipedia.org/w/index.php?title=Batalha_de_ Waterloo\&oldid=39197614. Acesso em: 15 jan. 2015.

Vol. 25 - Ano $44-n^{\circ} 2-2020$ 
CADEMARTORI, L. Períodos literários. 3. ed. São Paulo: Ática, 1987.

CONEGLIAN, S. M. G; SANTOS, C. A. dos; MELO, J. J. P. Reflexões sobre a vida de Descartes e o plano cartesiano. II Simpósio Nacional de Educação. XXI Semana de Pedagogia, 2010, Cascavel. Anais [...]. Cascavel: Universidade Estadual do Oeste do Paraná (UNIOESTE) / Campus de Cascavel, 2010. Disponível em: http://cac-php.unioeste.br/eventos/ iisimposioeducacao/anais/trabalhos/280.pdf. Acesso em: 23 nov. 2019.

ERUPÇÃO DO VESÚVIO DE 79. In: WIKIPÉDIA, a enciclopédia livre. Flórida: Wikimedia Foundation, 2014. Disponível em: http://pt.wikipedia.org/w/index. php?title=Erup\%C3\%A7\%C3\%A3o_do_Ves\%C3\%BAvio_de_79\&oldid=40362467. Acesso em: 15 jan. 2015.

ESTRELA POLAR. In: WIKIPÉDIA, a enciclopédia livre. Flórida: Wikimedia Foundation, 2014. Disponível em: http://pt.wikipedia.org/w/index.php?title=Estrela Polar\&oldid=40197569. Acesso em: 15 jan. 2015.

GONÇALVES DE MAGALHÃES. In: Brasil: Biblioteca Nacional Digital, 2019. Disponível em: http://bndigital.bn.gov.br/goncalves-de-magalhaes/. Acesso em: 5 jul. 2019.

JANIBELLI, I.; GUIMARÃES, D. Eclipses. Revista Eclética, Rio de Janeiro, n. 23, p. 43-45, jul./dez. 2006. Disponível em: http://puc-riodigital.com.puc-rio.br/media/11\%20-\%20eclipses. pdf. Acesso em: 5 jul. 2019.

LEIS DE KEPLER. In: WIKIPÉDIA, a enciclopédia livre. Flórida: Wikimedia Foundation, 2014. Disponível em: http://pt.wikipedia.org/w/index.php?title=Leis_de_ Kepler\&oldid=40799626. Acesso em: 15 jan. 2015.

LIMA, F. P.; ROCHA, J. F. V da. Eclipses Solares e Lunares. Física na Escola, São Paulo, v. 5, n. 1, p. 22-24, 2004. Disponível em: http://www.sbfisica.org.br/fne/Vol5/Num1/ v5n1a08.pdf. Acesso em: 15 jan. 2015.

LOPES, R. J. A lua tem um lado escuro. In: Revista Superinteressante, São Paulo, 25 fev. 2011. Disponível em: https://super.abril.com.br/ciencia/a-lua-tem-um-lado-escuro/. Acesso em: 25 nov. 2019.

MAGAlHÃES, D. J. G de. Suspiros Poéticos e Saudades. Brasília: Ministério da Cultura / Fundação Biblioteca Nacional / Departamento Nacional do Livro, [s.d.]. Disponível em: http://objdigital.bn.br/Acervo_Digital/Livros_eletronicos/suspiros_poeticos.pdf. Acesso em: 14 ago. 2014.

MALEBRANCHE, N. Diálogos sobre a metafísica e a religião: primeiro diálogo/Oficinas de tradução. [Departamento de Filosofia. Universidade Federal do Paraná]. Curitiba: Ed. 
SCHLA/UFPR, 2011. Disponível em: https://acervodigital.ufpr.br/bitstream/handle/1884/29815/ Malebranche_Di\%c3\%a1logos\%20sobre\%20a\%20Metaf\%c3\%adsica\%20e\%20a\%20Religi\%c3\%a3o. pdf?sequence=3\&isAllowed=y. Último acesso em: 25 nov. 2019.

MICHAELIS. Dicionário Brasileiro da Língua Portuguesa. Disponível em: https://michaelis. uol.com.br/. Acesso em: 16 nov. 2019.

MUSEU NACIONAL UNIVERSIDADE FEDERAL DO RIO DE JANEIRO. Pompeia e Herculano. Rio de Janeiro, [s. d]. Disponível em: http://www.museunacional.ufrj.br/guiaMN/ Guia/paginas/5/principal11.htm. Último acesso em: 25 nov. 2019.

RASTIER, François. Da semântica estrutural à semiótica das culturas. Revista Acta Semiotica et Lingvistica, João Pessoa, v. 24, n. 3, p.167-192, 2019. Disponível em: https:// periodicos.ufpb.br/ojs2/index.php/actas/article/view/51212/29719. Acesso em 16 set. 2020.

RASTIER, François. Semiótica das Culturas e cosmopolistismo: uma introdução. In: BATISTA, Maria de Fátima Barbosa de Mesquita; RASTIER, François (org.). Semiótica e cultura: dos discursos aos universos construídos. João Pessoa: Editora da UFPB, 2015a. p. 15-28.

RASTIER, François. Semiótica da Transmissão. In: BATISTA, Maria de Fátima Barbosa de Mesquita; RASTIER, François (org.). Semiótica e cultura: dos discursos aos universos construídos. João Pessoa: Editora da UFPB, 2015b. p. 479-508.

RASTIER, François. Entrevista com Rastier. Revista Acta Semiotica et Lingvistica, João Pessoa, v. 18, n. 1, p.136-144, 2013. Disponível em: https://periodicos.ufpb.br/ojs2/index. php/actas/article/view/18232/10312. Acesso em 16 set. 2020.

RENÉ DESCARTES. In: WIKIPÉDIA, a enciclopédia livre. Flórida: Wikimedia Foundation, 2015. Disponível em: http://pt.wikipedia.org/w/index.php?title=Ren\%C3\%A9 Descartes\&oldid=41082447. Acesso em: 15 jan. 2015.

REVISTA VEJA. Estrela Polar está diminuindo, afirmam astrônomos. São Paulo, 30 jan. 2012. Disponível em: https://veja.abril.com.br/ciencia/estrela-polar-esta-diminuindoafirmam-astronomos/. Acesso em: 25 nov. 2019.

SILVA, A. de S. e; BERTOLIN, R. Curso completo de Português. 1. ed. São Paulo: IBEP, 1999. (Coleção Horizontes).

TAQUARY, H. O. de B. Diálogo entre os saberes: as relações entre senso comum, saber popular, conhecimento científico e escolar. Universitas Relações Internacionais, Brasília, v. 5, n. 1/2, p. 97-104, jan./dez. 2007. Disponível em: file://C:/Users/Usuario/Downloads/3292809-1-PB.pdf. Acesso em: 25 nov. 2019.

ZÊNITE. In: WIKIPÉDIA, a enciclopédia livre. Flórida: Wikimedia Foundation, 2014. Disponível em: http://pt.wikipedia.org/w/index.php?title=Z\%C3\%AAnite\&oldid=40768810. Acesso em: 15 jan. 2015. 